\title{
PEMANFAATAN APLIKASI AUDACITY PADA PEMBELAJARAN ISTIMA' KELAS XI MAS MADINATUN NAJJAH
}

\author{
Amrina \\ Program Studi Pendidikan Bahasa Arab Institut Agama Islam Negeri Batusangkar \\ Email : amrina@iainbatusangkar.ac.id \\ Adam Mudinillah \\ Program Studi Pendidikan Agama Islam STAI AL-HIKMAH Pariangan \\ Email : adammudinillah@staialhikmahpariangan.ac.id \\ Syarifah Zaharani \\ Program Studi Pendidikan Bahasa Arab Institut Agama Islam Negeri Batusangkar \\ Email : syarifahzaharani@gmail.com
}

Diterima: 24-10-2021

Publish: 16-12-2021

\begin{abstract}
ABSTRACK
Istima 'is a very important way of mastering Arabic, by listening to a voice we will have another point of view in understanding and deepening Arabic. Listening techniques are also used at the lecture level, in this case there is no possibility for high school and elementary school levels to use the Istima technique in their learning process in order to improve understanding and proficiency in listening. Not only Istima 'In Arabic lessons there are various techniques or methods that can be used to broadly understand Arabic. There are many applications that can be used in this case, in this learning there are various divisions of skills to master Arabic perfectly, so that students not only master certain fields but are also proficient in writing, speaking, using Arabic. Among them are Maharah Kalam, Maharah Istima, Maharah Qiroah and Maharah Kitabah. In this scientific paper, the author is more focused on Maharah Istima' (hearing), this technique is very foreign to those who are not familiar with what Maharah is in language learning. this Arabic. In this modern era, there are many media that can be used for Maharah Istima', including Mixpad, Audacity, and others. In this Scientific Work, the author uses the Audacity Application as a Media in Maharah Istima' lessons, Mixpad applications can also be used in this Maharah lesson, by In other words, it's not just these 2 applications that readers can use in learning, but there are still many out there available various digital technologies and applications that are very useful for mastering and understanding Arabic lessons. This application can be used on mobile phones and laptops. This application can also capture sound from a headset connected to a laptop.
\end{abstract}

Keywords: Audacty, Maharah Istima ', Madinatun Najjah 


\begin{abstract}
Abstrak
Istima' merupakan cara yang sangat penting dalam menguasai Bahasa Arab, dengan menyimak suatu suara kita akan memiliki sudut pandang lain dalam memahami dan mendalami Bahasa Arab. Teknik menyimak juga digunakan pada jenjang perkuliahan, dalam hal ini tidak ada kemungkinan untuk jenjang SMA maupun SD menggunakan teknik Istima dalam proses pembelajaran mereka guna meningkatkan pamahaman dan kemahiran dalam menyimak. Tidak hanya Istima' Dalam pelajaran Bahasa Arab terdapat berbagai macam teknik atau cara yang bisa digunakan untuk memahami secara luas tentang Bahasar Arab. Banyak aplikasi yang bisaa digunakann dalam hal ini, pembelajaran ini terdapat berbagai pembagian keterampilan untuk menguasai Bahasa arab secara sempurna, agar siswa tidak hanya menguasai dibidang tertentu melainkan juga mahir dalam menulis, berbicara, menggunakan Bahasa arab. diantaranya ada Maharah kalam, Maharah Istima, Maharah qiroah dan Maharah Kitabah, Dalam karya tulis ilmiah ini penulis lebih mengarah kepada maharah Istima'(pendengaran), teknik ini sangat asing bagi mereka yang belum mengenal secara dalam tentang Maharah apa saja yang ada pada pembelajaran Bahasa Arab ini. Diera modern ini sangat banyak media yang bisa digunakan untuk Maharah Istima',diantaranya ada Mixpad, Audacity, dan lainnya, Pada Karya Ilmiah ini Penulis menggunakan Aplikasi Audacity sebagai Media dalam pelajaran maharah Istima', Aplikasi Mixpad juga bisa digunakan dalam pembelajaran Maharah ini, dengan kata lain bukan 2 aplikasi ini saja yang bisa pembaca gunakan dalam Pembelajaran, akan tetapi masih banyak diluar san tersedia berbagai teknologi digital dan aplikasi Yang sangat berguna untuk menguasai dan memahami Pelajaran Bahasa Arab. Aplikasi ini bisan digunakan pada handphone dan laptop. Aplikasi ini juga bisa menangkap suara dari headset yang disambungkan ke laptop.
\end{abstract}

Kata Kunci: Audacty, Maharah Istima', Madinatun Najjah

\title{
Pendahuluan
}

Dengan terus berkembangnya ilmu pengetahuan, Ada juga teknologi baru yang menandai kemajuan zaman, sampai sekarang Teknologi berkembang memasuki dunia digital. Pesatnya perkembangan dunia digital dan internet tentunya juga berdampak pada berbagai bidang termasuk pendidikan dan bisnis.Tren saat ini di kedua bidang tersebut bergeser dari yang semula tradisional (offline) menjadi digital (online). Di bidang pendidikan, teknologi digital sudah mulai dimanfaatkan untuk mendukung proses belajar mengajar,maupun sebagai sarana penunjang kegiatan belajar dan pekerjaan rumah. dan meningkatkan kinerja perusahaan. Teknologi berasal dari bahasa Yunani yaitu technologia 
(Nurkholis, 2013) (ditulis miring) yang merupakan gabungan dari dua kata yaitu techne (tulis miring) yaitu keahlian dan logia (tulis miring) yaitu mempelajari sesuatu atau cabang dari disiplin pengetahuan. Teknologi selalu berkaitan dengan perangkat atau alat bantu yang digunakan oleh manusia maupun spesies binatang. Menurut Anshari sebuah konsep telnologi merupakan penggunaan yang berkaitan dengan pengetahuan. (Aini, 2019), serta pengaruh terhadap kemampuan manusia terhadap cara mereka menubah keadaaan disekitarnya. Dalam dunia pendidikan teknologi sangat berperan penting, karena dengan adanya teknologi kemampuan anak dapat berkembang baik teknologi informasi, teknologi transportasi, teknologi medis dan teknologi lainnya (Nisa', 2020).

Seiring berjalannya waktu dari zaman tradisional kezaman modern ini memiliki peroses yang panjang dan menarik (Anshori et al., n.d.), perkembangan tidak hanya terjadi pada perubahan ekonomi dan stayle akan tetapi perubahan juga terjadi pada perkembangan teknologi yang setiap tahunnya memiliki perkembangan dan perubahan, perkembangan teknologi diera modern sekarang sangat memiliki dampak yang cukup besar terhadap pendidikan serta bisnis, tidak sedikit sekolah yang menggunakan teknologi digital sebagai sarana pendidikan, kebanyakan sekolah yang menggunakan teknologi digital memiliki kemampuan diatas rata-rata dibandingkan sekolah pada umumnya. karena sekolah akan berkembang jika terdapat perubahan pada cara mengajar serta menggunakan media apa saja dalam proses pembelajaran. Sesuai perkembangan zaman peserta didik akan tertarik dan memiliki minat yang lebih apabila menggunakan Teknologi dalam pembelajaran.

Dengan munculnya wabah Covid-19 membuat semua orang sulit dalam berinteraksi (Theopilus et al., 2020), semua orang diwajibkan berdiam dirumah hingga waktu yang telah ditentukan oleh pemerintah, mau tidak mau masyarakat akan mematuhi peraturan tersebut. Hal ini membuat sesama masyarakat sulit untuk berinteraksi sehingga menimbulkan jarak antara sesama tetangga, dengan adanya teknologi masyarakat akan dengan mudah untuk brinteraksi dengan orang terdekat mereka walapun tidak bertemu secara langsung. Tidak hanya terjadi pada lingkungan masyarakat, menjaga jarak juga terjadi pada jenjang pendidikan seperti 
dari paud hinga Mahasiswa, maka dari itu peran teknologi digital sangat penting diaplikasikan dilingkungan pendidikan.

Saat wabah covid-19 terjadi, proses pendidikan dilakukan secara daring dari tingkat SD sampai SMA. dalam pembelajaran proses dilakukan secara (Napitupulu, 2020) online dibutuhkan teknologi yang harus dipahami oleh siswa dalam pembelajaran. Dengan kata lain tegnologi digital bisa digunakan oleh semua kalangan dan tidak ada batasan usia terutama pelajar, peran orang tua dalam preoses pembelajaran juga penting, karena orang tua lah yang akan mengawasi peserta didik dalam pembelajarannya dirumah (Cahyati \& Kusumah, 2020). Para guru juga harus memerhatikan peserta didik dimana mereka tinggal serta kemampuan tempat tinggal mereka dalam mengakses internet. Kesulitan dalam jangkauan internet merupakan kendala yang sangat umum dan sulit dihadapinoleh peserta didik maupun para guru. Dalam permasalahan ini pemerintah harus turun dan bertindak untuk memperluas jaringan internet guna memperlancar proses pembelajaran peserta didik.

Keseharian masyarakat yang dulu susah sekarang mulai menjadi mudah dengan adanya teknologi, menggunakan teknologi semua pekerjaan menjadi tertolong, karena pengaruh teknologi (Kismiantini; Rina Dyah Rahmawati; Hartuti, 2010). Teknologi membantu memajukan semua aspek kehidupan manusia (M, 2012). Kehidupan sekarang tidak lepas dengan namanya teknologi, jarak yang jauh bukan penghaalang untuk berinteraksi dan berkomunikasi. dan batasan untuk mengetahui berbagai ilmu pengetahuan (Budiman, 2017). Ketika Penulis mulai mengenal Bahasa Arab dan memang seharusnya setiap muslim mempelajari dan mendalami Bahasa Arab (Uril, 2016), Penulis memutuskan melanjutkan Pendidikan kejenjang yang lebih Tinggi dan mengambil Jurusan Bahasa Arab.

Saat semester awal penulis tidak mengetahui sama sekali apa itu Maharah, setelah berjalan beberapa bulan disemester awal Penulis baru mengetahui apa itu dan Mahara dan Macam macam maharah. Saat ini penulis masih mendalami beberapa Maharah dan Manfaat mempelajari maharah tersebut, Salah satunya adalah maharah Istima'. Sebelum penulis masuk ketahap perkuliahan Penulis tidak tahu apa itu Mahrah Istima' dan setelah masuk pada perkuliahan Pendidikan Bahasa Arab penulis Baru mengetahui bahwa Mahara Istima' sangat penting 
diterapka dan dipelajari bagi setiap pelajar yang ingin menguasai Bahasa Arab. Maharah Istima' atau Keterampilan Mendengar bisa diterapkan pada kehidupan sehari hari menggunakan teknologi yang kita gunakan (Tami, 2020). Salah satunya aplikasi Audacity yang berguna untuk memutar dan mengedit video dengan cepat dan mudah (Aplikasi et al., 2021). Aplikasi ini bisa kita gunakan pada laptop atau handphone (Gide, 1967), karena penggunaanya cukup mudah dan simple yang bisa guru terapkan pada siswa yang sedang belajar Bahasa Arab. Guru wajib mengetahui teknologi apa saja yang harus digunakan untuk mengembangkan bakat anak terhadap pelajaran Bahasa Arab Terutama disekolah Madrasah Aliyah (Sumiharsono \& Hasanah, 2017).

Menurut Estu Pitarto didalam bukunya Make Audio Project With Audacity, Audacity adalah nama sebuah merek aplikasi yang didistribusikan GNU (General Public License) dan dikembangkan oleh kelompok yang sukarelawann. (License, 2014) . Audacity adalah aplikasi yang dibuat untuk mengolah suaraa menjadi fie atau menggabungngkan audio menjadi satu. Sedangkan pembelajaran Istima' adalah suatatu proses pembelajaran yang dilakukan dengan cara menyimak dengan menggunakan indra pendengaran .seseorang dapat dikatakan menyimak ketika ia mendengar dengan memusatkan perhatian kepada objek yang disimak sehingga mencapai maksud-maksud tertentu misalnya memahami aspek-aspek atau isi dari sebuah bahasa.

Dalam sebuah pembelajaran istima', audicity merupakan sebuah aplikasi yang sesuai jika digunakan pada pembelajaran istima (Ashadi, 2016)', karena audicity adalah sebuah aplikasi yang digunakan dalam bentuk suara yang diedit dan dimasukkan kedalam bentuk rekaman digital. Kelebihan dari aplikasi ini terdapat pada fitur dan kestabilan, pustaka yang digunakan tidak terlalu banyak dan waktu tunggunya juga tidak terlalu lama, dan kekurangannya yaitu antar muka penggunaanya yang sedikit kaku apabila dibandingkan dengan aplikasi sejenis di sistem operasi lain. Audacity memiliki beberapa fungsi, yaitu, membuat ringtone, menghilangkan vokal, memperlambat /mempercepat tempo lagu, menggabungkan dua file audio. Dalam menggunakan pembelajaran istima', audicity dapat membantu pengajar dalam memberikan pembelajaran dalam 
bentuk suara (audio) sehingga mempermudah pemahaman bagi anak yang memiliki gaya belajar audio visual.

Tidak hanya aplikasi Audacity yang bisa digunakan dalam pembelajaran, banyak aplikasi yang telah disediakan di Playstore yang bisa digunakan dalam pembelajaran (A. R. Putri \& Muzakki, 2019). Seperti aplikasi Animiz, Mixpad, Canva, Benime, Audacity, dan lain-lain. Aplikasi tersebut bisa digunakan sesuai dengan apa yang dibutuhkan pada proses pembelajaran, apabila guru ingin mengajarkan peserta didik membaca dan menulis maka penulis menyarankan pembaca menggunakan aplikasi animiz atau Benime dalam proses pembelajaran (Syahputri, 2018), agar siswa memiliki ketertarikan terhadap materi yang sedang dibahas. Begitupun dengan aplikasi lainnya, pada Aplikasi Audacity hanya menyediakan fitu pengedit Audio, maka pada aplikasi ini bisa diaplikasikan pada metode pembelajaran istima' atau hanya dengan pendengaran. Karena penulis menggunakan aplikasi Audacity sebahgai bahan pembahasan pada artikel ini, Karena sesuai dengan pelajaran yang dikaitkan yaitu pelajaran istima' atau belajar hanya menggunakan pendengaran saja dan menyimak apa yang didengar (Triyadi, 2015).

Dalam mata pelajaran Bahasa Arab terdapat berbagai keterampilan yang digunakan untuk memahami Bahasa Arab secara sempurna, diantaranya ada Maharah Kalam, Maharah Kiatabah, Maharah Qira'ah dan Maharah Istima', pada masing -masing Maharah memiliki keterampilan masing-masing untuk menguasai Bahasa Arab, pada maharah kalam siswa akan lebih focus pada keterampilan Berbicara menggunakan Bahasa arab, pada mata pelajaran ini guru akan lebih fokus mengajak siswa berbicara menggunakan bahasa arab dalam kehidupan sehari hari (Nur, 2017), media atau teknologi yang bisa digunakan dalam pelajaran ini adalah animasi yang mencintihkan bagaimana berbicara mrnggunakan bahasa arab dengan baik dan benar. Maharah Kitabah atau keterampilan dalam menulis, disini guru akan lebih fokus pada keterampilan menulis menggunkan bahasa arab dengan baik dan benar (Kuraedah, 2015), teknologi digital yang bisa digunakan pada Maharah ini seperti aplikasi benime yang menampilkan tulisan, tidak hanya benime yaagn bisa digunakan pada keterampilan ini masih banyak aplikasi yang ada di playstore yang bersifat menulis dan bisa dimanfaatkan untuk media 
pembelajaran maharah Kitabah. Maharah Qira'ah merupakan mata pelajaran yang membahas tentang keterampilan membaca, pada mata pelajaran ini guru akan lebih fokus pada kelancaran dan kemahiran membaca pada peserta didik (Ni et al., 2020), teknologi digital yang bisa digunakan pada mata pelajaran ini adalah aplikasi yang menampilkan tulisan seperti apllikasi Benime atau Animiz. Dan Maharah Istima' atau keterampilan mendengarkan merupakan keterampilan yang akan saya bahas pada Artikel ini (Jauhari, 2018), pembaca dapat membaca artikel ni jika ingin mengetahui tentang maharah istima' dan teknologi apa saja yang bisa digunakan pada mata pelajaran ini.

\section{Metode Penelitian}

Dalam penulisan karya ilmiah ini penulis memilih penelitian yang bersifat Deskriptif yang terjadi di Madrasah Madinatun Najjah. Di Madrasah Madinatun Najjah para siswa sudah mengenal tentang Bahasa Arab, akan tetapi belum sepenuhnya menerapkan Bahasa arab dalam kehidupan sehari hari. Dalam proses belajar mengajar peran yang paling penting adalah cerdasnya seorang guru dalam menggunakan media dan teknologi dengan cermat agar siswa mampu menguasai Bahasa arab dengan baik dan benar. Di madrasah ini dilengkapi fasilitas yang cukup canggih seperti labor komputer,labor bahasa, labor biologi, labor fisika dan labor kimiayang masing-masing labor memiliki fasilitas dan perlengkapannya masing-masing.

Madrasah ini memiliki 3 sampai 4 kelas setiap angkatan dan memiliki 2 jurusan yaitu Mipa dan Isos. Setiap lokal berisi maksimal 25-40 siswa dan memiliki Instruktur kelas masing-masing. Seperti instruktur kebersihan, keindahan, kerapian, keamanan dan kemasyarakatan, setiap instruktur wajib membuktikan dan memenuhi tanggung jawabnya masing-masing. Selain didalam kelas madrasah ini juga mengadakan pekan bahasa setiap minngu setelah jalan dan senam pagi. Seluruh siswa wajib menyaksikan pekan bahasa ini, karena disana siswa diajarkan percaya diri. Setiap minggu pekan bahasa ini menggunakan bahasa yang berbeda beda. Misalnya pekan pertama adalah bahasa Inggris maka guru yang bersangkutan akan menunjuk siswa yang bagus untuk penampilan pekan bahasa pada hari sabtunya. Begitu seterusnya untuk bahasa yang lain. Bahasa yang 
digunakan terdiri dari 3 bahasa yaitu Bahasa Inggris, Bahasa Indonesia dan Bahasa Arab.

\section{Hasil dan Pembahasan}

\section{Pengertian Aplikasi Audacity}

Audacity adalah editor audio digital sumber terbuka yang mudah diaplikasikan oleh semua kalangan. Aplikasi ini terdiri dari beberapa menu dan tools yang bisa digunakan untuk mengedit lagu atau audio, Aplikasi ini banyak digunakan dalam video pembelajaran karena aplikasi ini yang gratis dan open source Berikut beberapa cara yang bisa digunakan pada aplikasi Audacity :

- Pertama apabila kita ingin mengedit suatu audio maka kita harus membuka terlebih dahulu file yang akan diedit dengn klik menu file - open, lalu pilih audio yang akan diedit- klik open .

- Jika ingin memotong bagian yang tidak bagus maka klik selection tools pada menu - blok area yang ingin dihilangkan - klik gambar gunting, maka audio yang dipilih akan terhapus.

- Dan jika pada audio terdapat suara yang tidak diinginkan atau suara noise maka blok pada bagian suara yang terdapat noise kemudian klik effeknoises removal ( noise removal pada jendela, get noises propil diklik terlebih dahulu), proses akan berjalan, tunggu kemudian menu effek diklik - noise removal, atur ukuran noise reduction dan frequency smooting sesuai selera kemudian klik oke, maka suara noise akan hilang.

- Jika ingin menyimpan audio klik menu file - klik save project - klik save project as, dan beri nama pada audio tersebut - klik enter.

Masih banyak fitur fitur menarik yang disediakan oleh aplikasi ini (Saefullah, 2017), penulis hanya menulis beberapa fitur yang sering digunakan dalam mengedit Audio, adapun fitur dari aplikasi ini yaitu file - edit - select - view Transport - tracks - generate - effect - analyze - tools - help (Savitri et al., 2021) . Pada masing-masing menu memiliki fungsi dan kegunaannya masing-masing (Markhamah, 2010) yang bisa digunakan oleh pembaca atau guru yang mengajar menggunakan aplikasi ini. Dari masing-masing menu ini memiliki menu lagi salah satunya pada menu edit yang terdiri dari, Undo - Redo - cut -delete - copy - pasteduplicate- remove special- clip bundaries - Labels - labeled Audio - Metadata - 
preferences. Penulis berusaha untuk menulis beberapa fitur dan kegunaan agar pembaca mudah memahami dan memiliki rasa untukmencoba aplikasi ini. berikut beberapa menu pada aplikasi Audacity :

a) Menu file
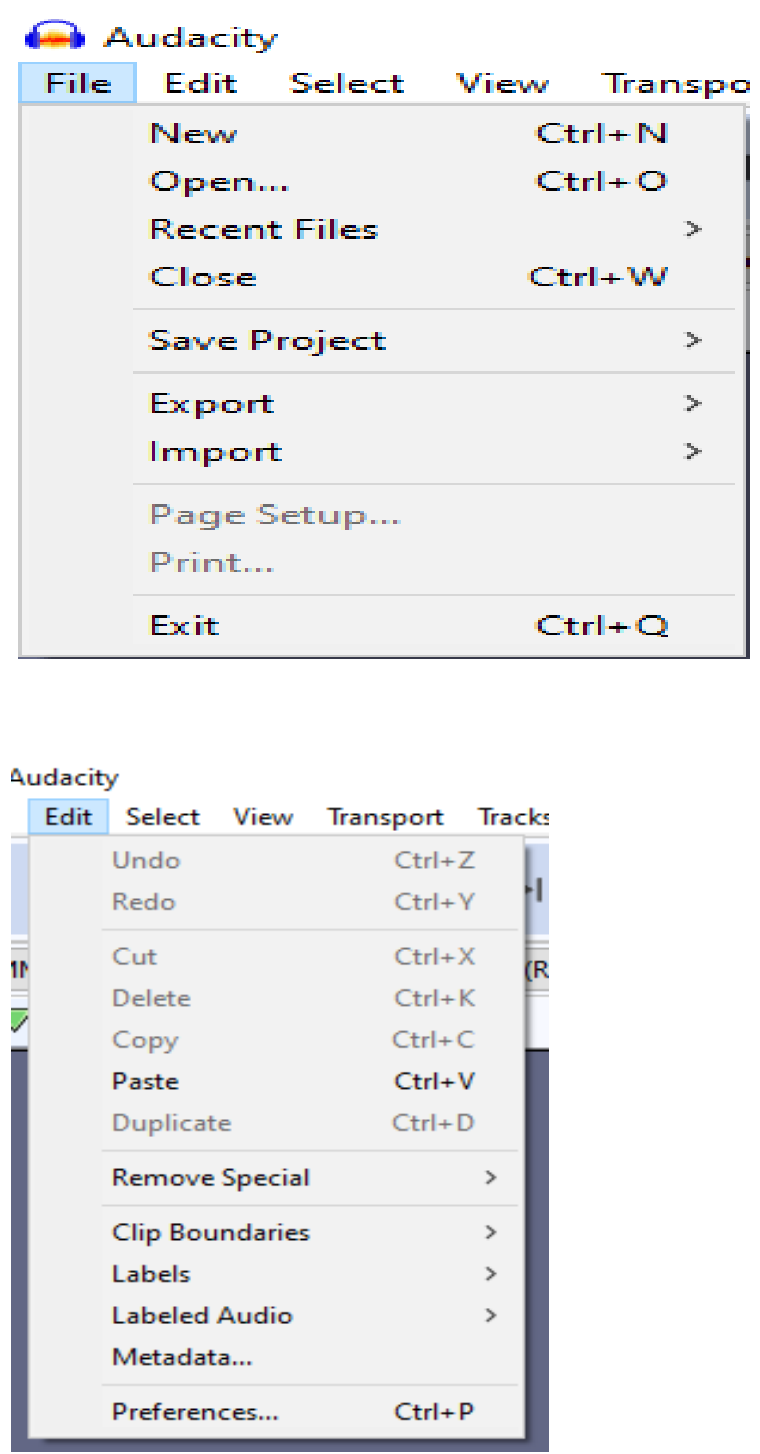

b) Menu Edit

c) Menu select 
ity

\begin{tabular}{|lr}
\hline Select View Transport Tracks Generate Effect \\
\hline All & Ctrl+A \\
None & > \\
Tracks & > \\
Region & > \\
Spectral & \\
Clip Boundaries & \\
\hline Cursor to Stored Cursor Position & \\
Store Cursor Position & Z \\
\hline At Zero Crossings &
\end{tabular}

d) Menu View

\begin{tabular}{l} 
View Transport Tracks Generate | \\
\hline Zoom \\
Track Size \\
Skip to \\
\hline History... \\
Karaoke... \\
Mixer Board... \\
Toolbars \\
Extra Menus (on/off) \\
Track Name (on/off) \\
Show Clipping (on/off) \\
\hline
\end{tabular}

e) Menu Transport

\begin{tabular}{|lr|}
\hline Transport Tracks Generate Effect \\
\hline Playing & $>$ \\
Recording & $>$ \\
Scrubbing & $>$ \\
Cursor to & \\
\hline Play Region & $>$ \\
\hline Rescan Audio Devices & \\
Transport Options &
\end{tabular}

f) Menu Tracks 


\begin{tabular}{|ll}
\hline Tracks Generate Effect Analyze & Too \\
\hline Add New & $>$ \\
\hline Mix & $>$ \\
Resample... & \\
\hline Remove Tracks & $>$ \\
\hline Mute/Unmute & $>$ \\
Pan & $>$ \\
\hline Align Tracks & \\
Sort Tracks & \\
\hline Sync-Lock Tracks (on/off) &
\end{tabular}

g) Menu generate

\begin{tabular}{l} 
Generate Effect Analyze Tools \\
\hline Add / Remove Plug-ins... \\
\hline Chirp... \\
DTMF Tones... \\
Noise... \\
Silence... \\
Tone... \\
Pluck... \\
Rhythm Track... \\
Risset Drum...
\end{tabular}

h) Menu Effect 


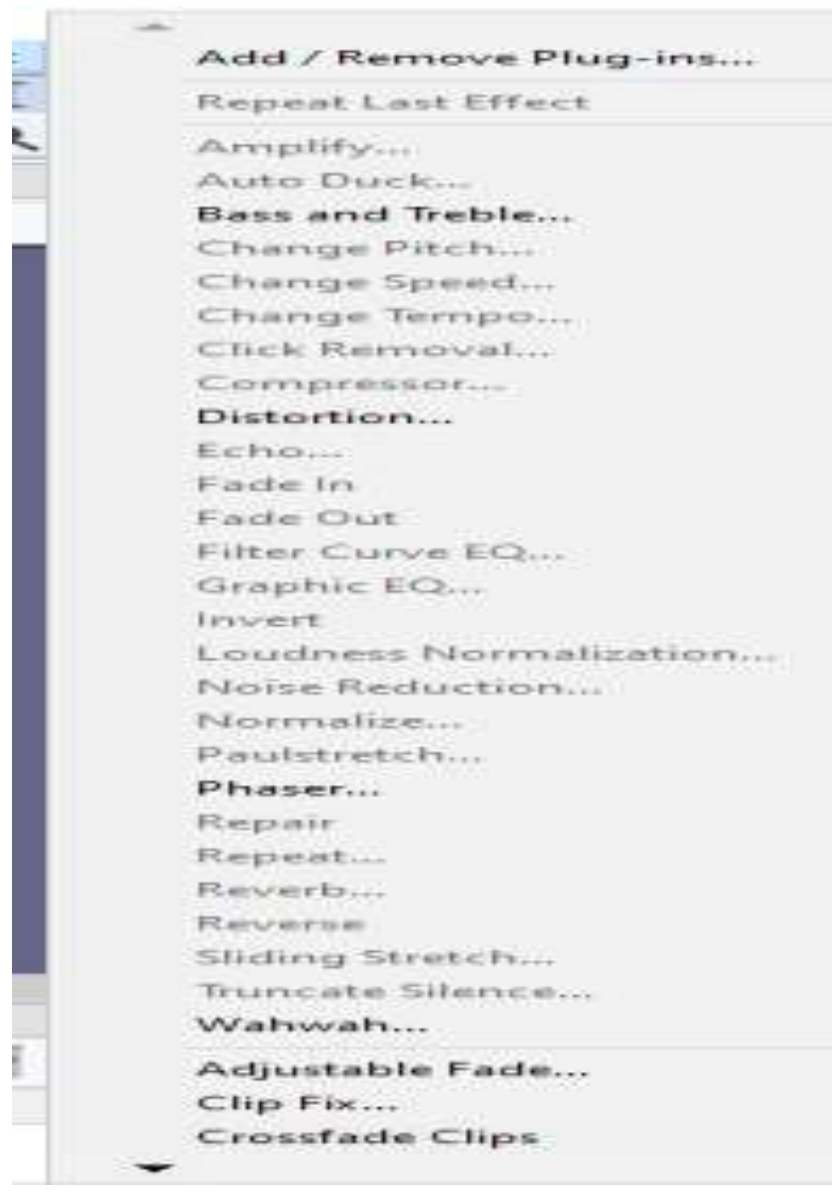

i) Menu Analyze

\begin{tabular}{l|l}
\hline Analyze Tools Help \\
\hline Add / Remove Plug-ins... \\
\hline Contrast... \\
Plot Spectrum... \\
Find Clipping... \\
\hline Beat Finder... \\
Label Sounds...
\end{tabular}

j) Menu Tools 


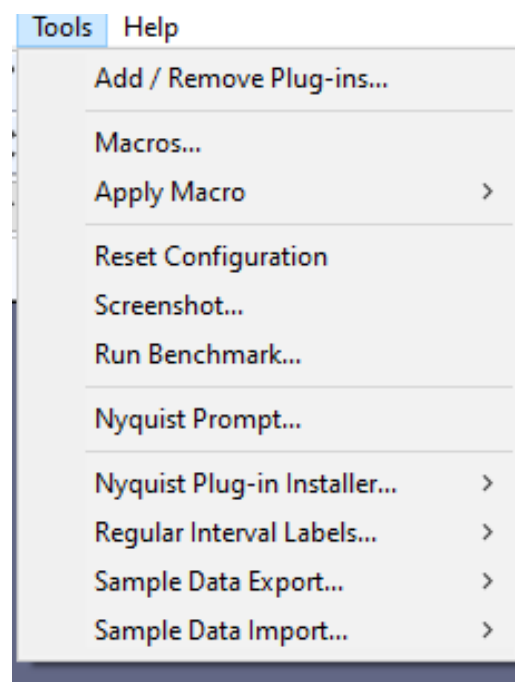

k) Menu Helpe

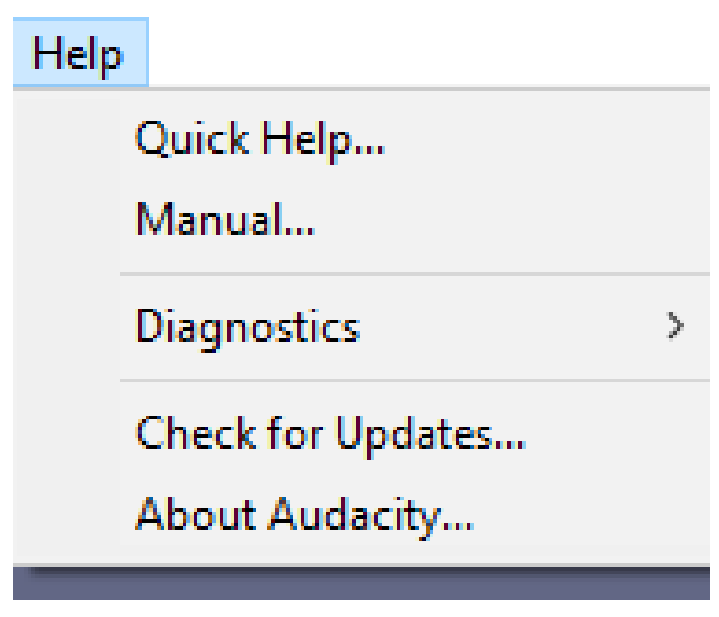

Selain dari menu menu diatas aplikasi audacity juga terdapat beberapa pitur yang menarik yang sudah disediakan dalam aplikasi ini, dan juga sering digunakan dalam editing audio. Diantaranya ada - Pause yang berguna untuk menghentikan perekaman suara sementara, disebelah fitur ini terdapat fitur - Play yang digunakan untuk memutar audio, kemudian ada fitur - Stop yang berguna untuk menghentikan Audio yang sedang diputar, - Skip To Star berguna untuk mengarahkan kembali pada awal Audio (Laras et al., 2016), - Skip To End berguna untuk mengarahkan pada akhir Audio, - Record berguna untuk memulai rekaman audio. - Selection tools berguna untuk memilih rentang audio yang akan diedit, envelope tools berguna untuk mengubah nada suara, - Draw tools berguna untuk memodifikasi nada suara pada titik titik tertentu, - zoom tool berguna untuk mengzoom bagian dari audio agar lebih jelas, zoom in ataupu zoom out bisa 
digunakan paa tools ini, -Time Shift Tool berguna untuk mengarah kan audio kekiri maupun kekanan, - Multi Tools mewakilkan semua menu tergantung pada tempat meletakkan mouse dan cara menggerakkannya. - Cut berguna untuk memotong audio yang tidak digunakan, - Copy berguna untuk mengcopy audio, - Paste berguna untuk mem paste Audio yang sudah ter Copy sebelumnya.

2. Pengaplikasian AplikasiAudacity pada pembelajaran Istima'

Pada proses belajar mengajar diruang kelas, media-media yang menarik sangat dibutuhkan agar anak tidak bosan dalam kegiatan belajar mengajar (Suhartina, 2018), jika media yang digunakan menarik maka anak akan cepat dalam menangkap materi yang diberikan (Kiromi \& Puji Yanti Fauziah, 2015) , begitu pun sebaliknya. Pentingnya seorang guru menguasai media-media menarik yang bisa membuat peserta didik betah dan menguasai materi tanpa paksaan.Pihak sekolah bisa menyarakan setiap guru dengan mata pelajaran tertentu menggunakan aplikasi Audacity untuk menambah wawasan dan kemampuan materi pembelajaran yang dikuasai oleh siswa. Salah satunya adalah mata pelajaran Bahasa Arab, beberapa daerah di Indonesia sudah mempelajari Bahasa ibunya Bangsa Arab ini sejak Madrasah Ibtidaiyah (Umi, 2018). Akan tetapi seiring dengan perkembangan zaman Bahasa ini semakin tidak disukai oleh pelajar (P. Putri, 2019), terutama pelajar yang tidak menempuh pendidikan pondok.

Disekolah yang penulis amati kemungkinan ada beberapa alasan yang diutarakan oleh peserta didik sebab mereka tidak menyukai Bahasa arab dan kemungkina akan menjaadi dasara semangatnya siswa dalm mempelajari Bahasa arab. Asumsi pertama pertemuan pertama atau kesan awal yang diberika saat pelajaran kurang menari. Asumsi kedua Susana linggkungan yang kurang mendukung untuk menerapkan Bahasa arab dalam keseharia. Asumsi ketiga Bahasa arab kurang moder dalam. Pada asumsi pertama pertemuan pertama kurang menarik (Hanifah, 2016), tidak jarang jika beberapa guru Bahasa arab memiliki sifat yang monoton dan garang dalam mengajar, dalam hal ini ketidak sukaaan pelajar pada guru akan secara otomatis membuat peserta didik tidak menyukai mata pelajaran yang dipegang oleh guru tersebut. Dinamika dalam permasalahan ini bisa berakibat fatal dalam kelangsungan pendidikan siswa , sebab pelajaran bahsa arab akan selalu berkesinambungan dari madrasah 
ibtidaiyah hingga Aliyah (Faridah, 2014) . Apabila sudah tidak paham pada pelajaran ibtidaiyah maka siswa akan kebingungan pada jenjang berikutnya. Untuk menimbulkan minat dan cinta terhadap Bahasa tersebut hendaknya guru lebih mampu memberikan kesan awal yang lebih menarik dan berinovasi serta mencciptakan kedekatan terhadap peserta didik. Jika tidak pelajaran Bahasa arab tidak akan mampu bersaing dengan pelajaran Bahasa asing yang dipelajari diindonesia (Syukri, 2009).

Pada asumsi kedua Susana linggkungan yang kurang mendukung untuk menerapkan Bahasa arab dalam keseharia (Ardi Widodo, 2006) . Pada permasalahan ini lebih dominan siswa berinteraksi di linkungan menggunakan Bahasa sehari-hari mereka,tanpa ada penekanan dari pihak sekolah (Suardi, 2014). Masalah ini berpengaryh besar terhadap pandangan peserta didik dala mempelajari tujuan dan fungsi Bahasa arab, hal ini juga dapat menimbulkan minat dan dan semangat dalam pembelajaran bahsa arab apabila pengaplikasian bahasa ini dalam kehidupan sehari-hari ditekankan pada peserta didik. Dan hendaknya peserta didik juga Pada asumsi ketiga Bahasa Arab tidak ada kesan keren dalam penggunaannya (Taquilla et al., 2018) , pada permasalahan ini pentingnya kreatifitas guru dalam mengajar Bahasa arab (Hasan, 2018), salah satu dengan menggunakan beberapa metode yang bisa membuat siswa bersemangat dalam belajar Bahasa arab, salah satunya dengan metode game, game yang digunakan dalam pembelajaran akan membawa kesan semangat dan seru dalam pelajaran (Fatmawati, 2020).

Seoranng guru setidaknya bisa menggunakan media teknologi dalam pembelajaran Bahasa arab agar proses belajar mengajar tidak terlalu monoton (Sholikhah, anna \& nur, 2020), contoh aplikasi yang bisa digunakan dala pembelajaran Bahasa arab adalah aplikasi Audacity, dengan menggunakan aplikasi ini siswa akan lebih sering mendengarkan Bahasa arab dengan mudah dan kapan saja, kosa kata yang digunakan akan lebih banyak didapat dan membiasakan siswa mendengar logat arab (IZZAN, 2011). Pada sekolah Ma Madinatun Najjah Bahasa arab sangat minim sekali, maka dari itu diperlukan peranan seorang guru dalam berkreasi dalam menciptakan pembelajaran yang bersifat kreatif,inovatif dan mudah dimengerti oleh setiap siswa, atau membuat game agar anak tidak bosan 
dalam proses belajar mengajar(Ali, 2018). guru bisa memanfaatkan aplikasi audacity sebagai sarana dalam pembelajarannya (Surya \& Kumala, 2015). Dengan menggunakan aplikasi ini kemungkinann minat siswa terhadap pembelajaran Istima' akan semakin meningkat.

\section{Kesimpulan}

Berdasarkan hasil dari pembahasan bahwa pentingnya peranan guru dalam mengetahui sarana dan prasarana yang bisa digunakan untuk pembelajaran agar siswa memiliki minat untuk lebih menguasai Bahasa Arab agar suasana dalam pembelajaran tidak monoton dan membuat siswa jenuh dengan pelajaran tersebut. Dapat penulis tarik kesimpulan bahwa : pemanfaatan aplikasi Audacity dalam proses pembelajaran Istima dapat meningkatkan minat belajar siswa. Aplikasi diatur sesuai tingkatan kemampuan masing-masing siswa agar siswa tidak gagal paham terhadap pelajaran.(Surya \& Kumala, 2015). Aplikasi ini dapat digunakan sebagai alat komunikasi siswa agar siswa tidak kaku dalam mendengarkan Bahasa Arab. Kemudian dapat Membuat siswa lebih mahir dalam mendengar dan memahami Bahasa Arab dengan cepat.

\section{Saran}

Semua guru harus memiliki usaha dan tekad agar peserta didik memiliki kemampuan dalam Bahsa Arab, guru bahasa diwajibkan menguasai teknologi agar siswa tidak bosan dan jenuh terhadap metode yang guru gunakan. guru juga harus mengeluarkan ide ide yang Inovatif dan kreatif guna meningkatkan minat dan semangat siswa dalam pembelajaran. Guru juga bisa menggunakan metode dongeng yang berisi tentang kisah kisah menarik kemudian diterjemahkan kebahasa indonesia sesuai dengan tingkat kemampuan peserta didik. Guru juga dapat menggunakan metode game pada akhir pembelajaran agar peserta didik kembali semangat untuk pembelajaran selanjutnya. Pada artikel yang penulis tulis, masih banyak kesalahan yang dilakukan oleh penulis, hendaknya kepada pembaca meneliti dan memeriksa kembali tulisan penulis,dan memberikan tanggapan terhadap tulisan penulis. 


\section{Daftar Pustaka}

Aini, D. N. dan C. N. (2019). Pengaruh penguasaan teknologi informasi dan prestasi belajar terhadap kesiapan kerja. Jurnal Pendidikan Manajemen Perkantoran, $4(2), 141$.

Ali, J. (2018). PERMAINAN SEBAGAI STRATEGI AKTIF LEARNING DALAM PEMBELAJARAN BAHASA ARAB. Osfhome, 6(1), 1-32. https://doi.org/10.17605/osf.io/jk5xh

Anshori, F. S., Majapahit, S. A., \& Kom, M. (n.d.). Aplikasi Pencatatan Penanganan Gangguan Pt. Telkom Regional Bandung. Aplikasi Pencatatan Gangguan PT. Telkom Regional Bandung, 1-8.

Aplikasi, D., Dan, A., Bagi, E., Mts, G., Tauhid, D., Inggris, P. B., \& Bojonegoro, I. P. (2021). PELATIHAN PENGGUNAAN VIDEO INTERAKTIF PEMBELAJARAN BAHASA Yuniarta Ita Purnama Chyntia Heru Woro Prastiwi Oktha Ika R Siti Ermawati Ayu Fitrianingsih Abstrak. 4, 26-33.

Ardi Widodo, S. (2006). Model - Model Pembelajaran Bahasa Arab. Al-'Arabiyah, 2(2), 2-14.

Ashadi. (2016). Pengembangan Media BBC ( Belajar Balita Cerdas) Rentang Umur 2-3 Tahun Berbasis Video Animasi. 2, 841-848.

Budiman, H. (2017). Peran Teknologi Informasi Dan Komunikasi Dalam Pendidikan. 8.

Cahyati, N., \& Kusumah, R. (2020). Peran Orang Tua Dalam Menerapkan Pembelajaran Di Rumah Saat Pandemi Covid 19. Jurnal Golden Age, 4(01), 4-6. https://doi.org/10.29408/jga.v4i01.2203

Data, B., \& Dan, P. (2006). Basis data peraturan dan perundang-undangan. Program, 1-14.

Faridah, A. (2014). PENDIDIKAN MADRASAH DI INDONESIA. Masalah Masalah Sosial, 5.

Fatmawati, D. (2020). Dewi Fatmawati / 21. 3.

Gide, A. (1967). 済無No Title No Title No Title. Angewandte Chemie International Edition, 6(11), 951-952., 5-24.

Hanifah, U. (2016). PENERAPAN MODEL PAIKEM dengan MENGGUNAKAN MEDIA PERMAINAN BAHASA dalam PEMBELAJARAN BAHASA ARAB. Ilmu Tarbiyah "At-Tajdid," 301-330.

Hasan, H. (2018). Keterampilan Mengajar Bahasa Arab Materi Istima Menggunakan Media Lagu. Al Qalam: Jurnal Ilmiah Keagamaan Dan Kemasyarakatan, 15(28), 127. https://doi.org/10.35931/aq.v0i0.7

IZZAN, A. (2011). Metodelogi Pembelajaran Bahasa Arab.

Jauhari, Q. A. (2018). Pembelajaran Maharah Istima di Jurusan PBA UIN Maulana Malik Ibrahim Malang. Jurnal Tarbiyatuna, 3(1), 129-152. http://ejournal.kopertais4.or.id/mataraman/index.php/tarbiyatuna/article/v iew $/ 3440$

Kiromi, I. H., \& Puji Yanti Fauziah. (2015). Pengembangan Media Pembelajaran Big Book Untuk Membantu Karaker Anak Usia Dini. Jurnal Pendidikan Dan Pemberdayaan Masyarakat, 2(1), 107-121.

Kismiantini; Rina Dyah Rahmawati; Hartuti, E. R. (2010). Dunia Teknologi Informasi dan Komunikasi. In Pusat Perbukuan Kementerian Pendidikan Nasional (Vol. 53, Issue 9). 
Kuraedah, S. (2015). APLIKASI MAHARAH KITABAH DALAM PEMBELAJARAN BAHASA ARAB Sitti Kuraedah. Al-Ta'dib: Jurnal Kajian Ilmu Pendidikan, IAIN Kendari, 8(2), 82-98.

Laras, S., Nada, A., Nada, U., Menggunakan, K., \& Frekuensi, K. (2016). SKRIPSI Oleh : IRFAN KHAIRUL AMAL.

License, G. G. P. (2014). GNU General Public License. 25.

M, M. (2012). Perkembangan Teknologi Dalam Industri Media. Jurnal Teknik Industri, 12(1), 57. https://doi.org/10.22219/jtiumm.vol12.no1.57-64

Markhamah, N. (2010). Aplikasi multimedia Education Games untuk anak usia dini.

Napitupulu, R. M. (2020). Dampak pandemi Covid-19 terhadap kepuasan pembelajaran jarak jauh. Jurnal Inovasi Teknologi Pendidikan, 7(1), 23-33. https://doi.org/10.21831/jitp.v7i1.32771

Ni, K., Rizqi, M. R., \& Ismawati, E. (2020). Implementasi Metode Takrir Pada Materi Fi ' Il Dalam Pembelajaran Maharah Qiroah Bahasa Arab Siswa Kelas X Smk Nu 1 Sukodadi. Al-Fakkaar: Jurnal Ilmiah Pendidikan Bahasa Arab, 1(2), 1-17.

Nisa', L. (2020). Pemanfaatan Teknologi Dalam Pendidikan Anak Usia Dini. ThufuLA: Jurnal Inovasi Pendidikan Guru Raudhatul Athfal, 8(1), 001. https://doi.org/10.21043/thufula.v8i1.6283

Nur, H. (2017). Penerapan Metode Muhadatsah Dalam Meningkatkan Hasil Belajar Maharah Kalam Peserta Didik. Lentera Pendidikan : Jurnal Ilmu Tarbiyah Dan Keguruan, 20(2), 177-187. https://doi.org/10.24252/lp.2017v20n2i4

Nurkholis. (2013). PENDIDIKAN DALAM UPAYA MEMAJUKAN TEKNOLOGI Oleh: Nurkholis Doktor Ilmu Pendidikan, Alumnus Universitas Negeri Jakarta Dosen Luar Biasa Jurusan Tarbiyah STAIN Purwokerto. 1(1), 24-44.

Putri, A. R., \& Muzakki, M. A. (2019). Implemetasi Kahoot sebagai Media Pembelajaran Berbasis Digital Game Based Learning dalam Mengahadapi Era Revolusi Industri 4.0. Prosiding Seminar Nasional Universitas Muria Kudus, 17. http://pgsd.umk.ac.id/files/prosiding/2019/27__Aprilia_Riyana.pdf

Putri, P. (2019). RANCANG BANGUN MEDIA PEMBELAJARAN BAHASA ARAB UNTUK ANAK USIA DINI BERBASIS ANDROID. 10.

Saefullah, I. (2017). Membuat Buku Digital Mandiri.

Savitri, H., Sundari, R., Marlina, I., Siggi, E., \& Hernanda, R. (2021). OPTIMALISASI MEDIA PEMBELAJARAN BERBASIS VIDEO ANIMASI SEBAGAI SOLUSI PEMBELAJARAN DI TENGAH PANDEMI COVID-19. 2(1), 18-22.

Sholikhah, anna \& nur, ikhwan \& vinda afifah. (2020). KAJIAN TEORITIS MEDIA PEMBELAJARAN BAHASA ARAB.

Suardi, I. (2014). Model Pembelajaran Bahasa Arab.

Suhartina, M. \&. (2018). Media Pembelajaran Berbasis Teknologi Informasi dalam Meningkatkan Minat Belajar Akidah Akhlak. 11.

Sumiharsono, R. dan, \& Hasanah, H. (2017). Media Pembelajaran: Buku Bacaan Wajib Dosen, Guru dan Calon Pendidik. In Cetakan Pertama. https://books.google.co.id/books?id=VJtlDwAAQBAJ\&printsec=frontcover\&d $\mathrm{q}=$ media + pembelajaran\&hl=id\&sa=X\&ved=0ahUKEwiCdHIr7flAhXZiHAKHeRCBhUQ6AEIMjAB\#v=onepage $\& \mathrm{q}=$ media pembelajaran\&f=false

Surya, W., \& Kumala, J. (2015). Pembuatan Media Pembelajaran Interaktif Pengenalan Benda Berbasis Game Untuk Anak. 4(2), 1-14. 
Syahputri, N. (2018). RANCANG BANGUN MEDIA PEMBELAJARAN MATEMATIKA SEKOLAH DASAR KELAS 1 MENGGUNAKAN METODE DEMONSTRASI Nita. JSIK (Jurnal Sistem Informasi Kaputama), 2(1), 89-95.

Syukri, K. (2009). Hubungan penggunaan strategi pembelajaran bahasa dengan tahap penguasaan Bahasa Arab. 41-56.

Tami, T. (2020). Pengembangan Media Pembelajaran Bahasa Arab Berbasis Audio Visual Untuk Meningkatkan Maharah Istima' Pada Siswa-Siswi Madrasah Ibtidaiyah. 3.

Taquilla, P. P. O. R., Colas, S. I. N., \& Esperas, N. I. (2018). 103.10 (pp. 12-13).

Theopilus, Y., Yogasara, T., Theresia, C., \& Octavia, J. R. (2020). Analisis Risiko Produk Alat Pelindung Diri (APD) Pencegah Penularan COVID-19 untuk Pekerja Informal di Indonesia. Jurnal Rekayasa Sistem Industri, 9(2), 115-134. https://doi.org/10.26593/jrsi.v9i2.4002.115-134

Triyadi, S. (2015). Efektivitas Penggunaan Media Audio-Visual Untuk Meningkatkan Keterampilan Menyimak Siswa Pada Mata Pelajaran Pendidikan Bahasa Indonesia. Jurnal Pendidikan Unsika, 3(2), 188-199. https://journal.unsika.ac.id/index.php/judika/article/view/215

Umi, H. (2018). ANALISIS PEMBELAJARAN MUFRODAT DAN STRUKTUR BAHASA $\begin{array}{llll}A R A B & D I & M A D R A S A H & \end{array}$ http://repository.radenintan.ac.id/id/eprint/3266

Uril, B. (2016). Bisa Bahasa Arab Bukan Hanya Mimpi (UNSPECIFIED (ed.); Pertama). http://repository.uin-malang.ac.id/3771/7/3771.pdf 